\title{
DEXTER E O SERIAL KILLER QUE CONSOME SERIAL KILLERS: Uma representação de metaconsumo?
}

\author{
Danielle Brasiliense ${ }^{1}$ \\ Ana Lucia Enne ${ }^{2}$
}

\begin{abstract}
Resumo: A partir de uma instigante sugestão de Brian Jarvis de que é possivel compreender a ação do consumidor contemporâneo como algo similar aos rituais de aniquilação do outro empreendidos por um serial killer, apresentamos, neste artigo, algumas interpretações sobre o consumo atual tomando como referência analítica a série televisiva Dexter. Nela, a personagem central encarna um serial killer que mata serial killers, nos levando a indagar acerca da possibilidade deste herói ambíguo funcionar como representação dos dilemas do consumidor contemporâneo.
\end{abstract}

Palavras-chave: Representação. Consumidor. Dexter. Serial killer. Identidades.

\section{Abstract:}

Key-words: Advertising. Consumption. Brands.

\section{Introdução}

Em seu artigo “Monster Inc.: serial killers and consumer culture”, Brian Jarvis (2007) propõe uma interessante relação para pensar o lugar do consumidor na sociedade contemporânea: a equiparação do ato de consumir, ritualístico e serializado, ao modus operandis de um serial killer. Para propor essa hipótese, Jarvis toma como exemplo filmes que têm serial killers como personagens principais, tentando indicar uma noção de contigüidade entre o ato de consumir e o ato de consumar operações repetitivas de morte e eliminação do outro.

Se concordamos com o autor, podemos partir de um interessante pressuposto para pensar as relações de consumo na sociedade contemporânea: com+sumir, etimologicamente, é uma experiência socializada de extinguir aquilo que foi produzido, natural ou culturalmente, através das mais diversas práticas. Inserida na cultura, a

\footnotetext{
${ }^{1}$ Doutoranda em Comunicação pela ECO/UFRJ.

Email: dabrasiliense@gmail.com.

${ }^{2}$ Professora de Estudos de Mídia e do PPGCOM/UFF.

Email: anaenne@terra.com.br.
} 
vivência do consumo implica em relações de significação e representação, ou seja, falam do mundo e marcam, no mundo, nossos lugares de memória, projeto e identidade. Como indicam Mary Douglas e Baron Isherwood, "os bens são codificados para a comunicação. Têm outros usos práticos, mas o que precisamos investigar é como permitem que um consumidor se envolva com outros numa série de trocas” (2006:39). Portanto, nos lembram os dois autores, "os bens são neutros, seus usos são sociais" (idem: 36). Assim, o consumo, para além de uma experiência econômica, seria claramente uma prática social e cultural, que implica em lidar com instâncias reguladoras e transgressoras, como a ordem e a desordem, com a configuração das identidades e das alteridades. Este é, basicamente, o objetivo deste artigo: pensar as práticas de consumo como um exercício de negociação e também de eliminação do outro na construção das identidades culturais.

Para desenvolvermos nossa reflexão sobre essa temática, escolhemos discutir essa aproximação entre consumo seriado e práticas culturais analisando a série televisiva Dexter, lançada em julho de 2007 pela produtora americana Show Time e transmitida pelo canal FX de TV fechada, que vem gerando grande audiência, especialmente entre os fãs de filmes policiais que contam histórias de crimes provocados por serial killer. A série já teve três temporadas exibidas até o final do ano de 2008. Michael C. Hall é o ator principal que vive a personagem Dexter Morgan, um perito da polícia, especialista em sangue, que foi treinado por seu pai, Harry Morgan, para matar os assassinos mais cruéis da cidade de Miami, o que ele realiza através de um modus operandis característico de um serial killer. Trata-se, portanto, de um programa televisivo que tem como "herói” um serial killer que mata serial killers.

Nossa proposta, neste artigo, é pensar como a questão do ritual, na série, implica em uma forma de consumo do outro que permite que a identidade do self, no caso da personagem principal, se constitua. Essa identidade, necessariamente, precisa dialogar com os campos da ordem e da desordem. Assim, estamos partindo de um primeiro ponto: se entendemos o serial killer como um tipo de consumidor seriado, como podemos pensar a figura de Dexter Morgan, em seu esforço de conjugar norma e desvio através da prática seriada do consumo de outros corpos? E como podemos, a partir disso, pensar a figura do consumidor contemporâneo, representado em especial pelo fã da série, que se identifica e se reconhece na prática ritualizada de seu ídolo, também ele, o fã, um consumidor seriado de corpos ficcionais que se apresentam nas múltiplas faces 
da mídia contemporânea? Para pensar tais questões, começaremos primeiramente com uma reflexão sobre a série Dexter.

\section{Dexter e o ambíguo jogo de constituição da personagem central}

A série Dexter, como indicamos acima, revela uma identidade monstruosa diferente, um monstro/herói, um serial killer justiceiro que extermina outros serial killers. Os crimes monstruosos de Dexter não são crimes sem motivo, têm o objetivo de manter a ordem. Sua tarefa é realizada sempre de maneira sistemática e compreende as seguintes etapas: surpreender suas vítimas com uma injeção anestésica no pescoço, amarrá-las com plásticos, imobilizá-las em uma cama improvisada e, logo depois de sacrificá-las, fatiar seus corpos. Esses atos não deixam de ser um ritual macabro de monstruosidade, mesmo que seu objetivo seja a limpeza de um mundo infectado por pessoas ruins. Não é por menos que Harry, pai de Dexter e o grande responsável pela construção e desenvolvimento da identidade monstruosa do filho, ao se deparar com a cena ritualística de morte criada por sua criatura, se suicida, pois percebe que seus objetivos de promover a ordem se tornam impossíveis sem a existência de uma desordem, como a monstruosidade. Assim, podemos observar que a vida da personagem Dexter é uma busca por entender o que pode ser considerado ordem e o que realmente pode ser denominado desordem, monstruosidade ou anormalidade. Assim, Dexter marca esse lugar com a ambigüidade de uma identidade monstruosa e não-monstruosa ao mesmo tempo.

A série Dexter nos parece um produto de comunicação de massa importante a ser analisado, pois, com sua grande audiência, todos os sentidos ali apresentados estão se reconfigurando de alguma forma para os telespectadores. Então nos perguntamos: o que Dexter nos apresenta? Que sentidos esse programa produz em sua exibição? Como o senso comum, em meio à tamanha ambigüidade, é administrado? Como é apresentada de fato a identidade da personagem Dexter e que caminhos procura tomar?

Foram diversas as questões que despertaram o interesse por esta série. ${ }^{3}$ Em primeiro lugar, a questão do equilíbrio da monstruosidade dado pelos ideais de uma ordem cuja referência é a família. Dexter, o serial killer, é moldado pelo poder do pai, Harry, o policial que o adota e vira uma referência de vida equilibrada pela normalidade. Um dos mais importantes princípios impostos pelo personagem de Harry

\footnotetext{
${ }^{3}$ Se neste artigo nosso foco de reflexão recai sobre a relação entre a série Dexter e o consumo, em outro trabalho buscou-se analisar de forma mais detalhada a relação entre ordem, desordem e a questão da monstruosidade em Dexter (BRASILIENSE, 2009).
} 
para a sobrevivência do filho Dexter é a família, referência e base, para que o monstro serial killer que vive dentro dele não seja despertado, a não ser em um caso de necessidade e emergência social. O pai, que só aparece nas lembranças de Dexter, o aconselha à beira da morte a se prender à sua irmã Debra como fonte de equilíbrio. Esta série deixa clara a idéia de família como pilar de sustentação de uma ordem.

É através de seus rituais macabros que a personagem Dexter se constitui em termos de identidade. E tal formulação, necessariamente, leva em consideração o mundo em que tal identidade se constitui. Este mundo é normatizado por valores que implicam, como dissemos acima, em lugares de ordem e equilíbrio. Assim, a constituição da identidade de Dexter implica no reconhecimento da alteridade, do lugar do outro. Para ser configurado como aquele que representa a desordem, em seu papel de serial killer, Dexter precisa reconhecer as regras e limites do mundo da ordem, representado pela família, pelo ambiente do trabalho, pelos seus amigos. E todo seu esforço é o de encaixar-se nesse mundo, lutando pela sua preservação - ao eliminar os serial killers que o comprometem -, ao mesmo tempo em que, ambiguamente, o coloca em suspenso. A trajetória de Dexter, em sua formulação identitária, assim como a de todos nós, só se completa na relação com o outro, que nos fornece os parâmetros para nosso posicionamento - ainda que transitório - no mundo.

A série, de modo geral, reitera o lugar do pai como referência de ordem, de normalidade e verdade absoluta. Dexter é adotado por um policial aos três anos de idade, após ser encontrado dentro de um contêiner banhado pelo sangue de sua mãe, brutalmente morta e fatiada por uma serra elétrica. Harry Morgan, um policial experiente, percebe com o passar dos anos que seu novo filho tem obsessão por sangue e, conseqüentemente, fantasias sobre capturar presas e matá-las. O pai o julga como um nato serial killer e constrói uma forma de deter seus impulsos. Preocupado com o futuro de Dexter, Harry formula alguns códigos de conduta moral e ensina ao menino que matar uma pessoa não é apenas assassiná-la, mas privá-la de tudo que ela pode se tornar um dia, e, portanto, o jovem só deveria usar uma arma contra alguém se houvesse um objetivo de salvar a si mesmo ou a sociedade, pois, caso contrário, isso seria só um crime e ele se tornaria um assassino cujo futuro estaria restringido à prisão e à morte. Harry aproveita os desejos sanguinários de Dexter para formar um serial killer de serial killers, um monstro invisível na sociedade, cujo distúrbio interno é regulado por um código de normalidade, já que, para o policial experiente, o destino do filho não poderia ser mudado. Dexter é o herói com identidade secreta assim como o Super-Homem, ou o 
Homem-Aranha, mas a contradição de bondade absoluta é o seu diferencial, pois Dexter é um monstro/herói, um serial killer como suas vítimas, mesmo com intuito de ajudar a sociedade, eliminando pessoas com as mesmas características e instintos assassinos que os delas. O mistério de Dexter, diferente dos comuns super-heróis, é guardar dentro de si um monstro que só se revela em favor da sociedade. Nenhum outro herói é ao mesmo tempo monstro, ao contrário, os enredos geralmente colocam vilãos e heróis em lugares separados. Dexter é, portanto, uma novidade televisiva nesse sentido.

Assim, a série Dexter é um produto de comunicação de massa que propõe uma abordagem diferente. Não é uma série ou uma história como as outras, pois o lugar do herói é ambíguo. Sem dúvida, os episódios são marcados por personagens estereotipados em produções americanas, como latinos na cidade de Miami, por exemplo. Mesmo sob essa condição, a série permite que os telespectadores tenham uma quebra do senso comum, pois os personagens tradicionais deste tipo de entretenimento fazem com que o contraditório Dexter se destaque significativamente. Parece-nos, então, um marco do olhar da diferença entre o senso comum e a percepção da contradição da realidade. Pensamos isso mediante a idéia de que o senso comum enquadra as realidades ambíguas que nos cercam: monstros são absolutamente maus e heróis são completamente bons.

É interessante perceber que em Dexter, os telespectadores não torcem por ele apenas por ele ser um justiceiro, mas por demonstrar toda a questão do cotidiano, pois embora ele seja um assassino, ele é uma figura que demonstra o comum, com sua vida no trabalho, nas relações com a namorada, nos seus erros e trapalhadas. O que une Dexter com o telespectador são as situações de vivência do cotidiano e suas experiências com o acaso. As cenas musicadas produzidas para abertura dos episódios demonstram essa relação entre cotidiano e monstruosidade. Dexter desperta pela manhã com um mosquito que morde seu braço. Com um forte e certeiro tapa ele mata o inseto. Essas duas primeiras cenas marcam a precisão do personagem em eliminar quem o incomoda, mas, ao mesmo tempo, passa também a idéia de que é alguém que acorda sendo picado por um mosquito, algo absolutamente normal. Após levantar-se, ele se barbeia, seu rosto é cortado e o sangue pinga na pia. As cenas mostram sua relação com o sangue, mas, mesmo em procedimentos cotidianos e aparentemente normais, as imagens são carregadas de ambigüidade. Ele corta bifes, frita-os e os devora como um monstro carnívoro. Quebra um ovo e o come frito com catchup, que marca a presença da cor vermelha do sangue. Faz café na cafeteria, que tritura os grãos, corta uma fruta e 
a espreme para o suco, como se fizesse o mesmo trabalho com corpos de pessoas. Enrola o fio dental nos dedos e o passa nos dentes com intensidade, laça os sapatos e os amarra com força, põe a camisa, fecha a porta do apartamento com a chave e sai com ar de felicidade e bom-humor. Sangue, cortes, amarras, mordida feroz, agressividade. Despertar do sono, barbear-se, tomar café da manhã e se vestir. Essas cenas revelam o cotidiano comum da maioria americana, isso aproxima a personagem de seu público observador, inclusive revelando práticas de consumo alimentar, de vestuário, de objetos manipulados. Mas o que desperta a curiosidade são as dualidades que propõem essas filmagens, pois, ao mesmo tempo, mostram o cotidiano e a preparação de um típico serial killer com seus atos, gostos e vestimentas, um ser assustador, ou um homem solteiro comum, que acorda e se prepara para sair de casa, revelando, por seus hábitos, seu estilo de vida.

O enquadramento de Dexter na vida de normalidade se dá na sua relação com os companheiros de trabalho, onde ele é o camarada que distribui rosquinhas todos os dias pela manhã, e também na convivência com sua namorada Rita e seus filhos. Rita é uma mulher separada de um presidiário, com dois filhos pequenos. Uma mulher comum, trabalhadora, dona de casa e com ar contido, sem muitas vaidades. Dexter a considera a mulher ideal para ter um relacionamento, pois, assim como ele, não se interessa por grandes emoções e ambições na vida ordenada pela normalidade. Depois da morte do pai, Dexter se apoia nesta família e conta também com sua irmã Debra para não se desviar dos códigos e matar qualquer pessoa somente por prazer. Basta, então, seguir regras de condutas receitadas por Harry, para não se desviar do caminho do bem, pois, mesmo que viva cometendo crimes, o importante é que este mal não custe nunca a vida de inocentes.

O que Harry, com seu poder de pai, chama a atenção de Dexter nos momentos em que o ensina a ter um comportamento normal, é jamais se desviar ou surpreender o mundo com sua monstruosidade. Ele deve, assim, deixar seu lado impuro congelado, escondido, enquanto se relaciona com a sociedade que crê em padrões de pureza. Dexter vive uma vida de mentiras, superficial, um "garotinho de madeira”, como ele mesmo diz na série, com corpo condenado a uma moldura, um engessamento. A afirmação da monstruosidade de Dexter separada da sua auto-sensação interna se contrapõe ao vazio de raciocínio lógico por conta da existência da crença numa verdade chamada normalidade. 
Ele só se realiza, e se sente pleno enquanto sujeito, quando sai para realizar seu ritual de morte. Antes da cerimônia propriamente dita (quando Dexter mata seu alvo em um ambiente coberto por plásticos, utilizando instrumentos adequados, não sem antes retirar uma amostra do sangue para guardar, em uma lâmina, como parte de uma coleção de lâminas com o sangue de suas vítimas), Dexter mantém com a vítima uma relação de expectativa, desejo e preparação. Se compreendermos que o momento da morte do outro é o instante do consumo do outro, precisamos compreender também que há um período que antecede o consumo em que o outro é o objeto do desejo a ser saciado. Para isso, Dexter se prepara minuciosamente. Escolhe o lugar ideal para a realização do ritual, averigua se seus instrumentos estão em perfeitas condições, mapeia o cotidiano de seu alvo para escolher o momento exato de agir. São etapas que precedem o instante auge de sua ação, em que a personagem vivencia a adrenalina da expectativa. O ápice deste processo é a consumação do ritual da morte. Quase orgasticamente, Dexter demonstra, em suas expressões e atitudes, o papel do sujeito que só se satisfaz quando se apropria e consome o outro, no caso suas vítimas fatais. É neste instante que sua identidade se concretiza e ele encontra seu lugar no mundo. E a satisfação obtida com essa prática confere a ele um prazer tão grande que gera, em seguida, a frustração pelo seu fim e a necessidade premente de passar de novo por tal experiência. Assim, Dexter estabelece com suas vítimas, de forma semelhante ao que acontece com os serial killers de modo geral, uma relação de expectativa, satisfação, frustração e necessidade de repetição constante de todo o processo ritualístico para que novamente a sensação de prazer e satisfação possa ser vivenciada. É enquanto assassino, no ato de consumir o outro, que Dexter se realiza e se configura enquanto sujeito. Mas é somente na relação com o outro, seu alvo, seu objeto de desejo e consumo, que tal constituição se completa. Dexter só é Dexter, em sua subjetividade mais plena, quando consome o objeto de seu desejo.

Podemos dizer, a partir dos pontos que elencamos acima, que Dexter é um produto da diferença, não é uma série ou uma história como as outras já exibidas na TV a respeito de assassinos, ou serial killers. Dexter é a imagem da ambigüidade e da realidade contraditória. Trata-se da exibição de uma identidade em negociação e não totalmente cristalizada como se costuma fazer em programas massificados pela mídia.

\section{O consumidor contemporâneo como serial killer}


A partir das reflexões que propusemos sobre a série, queremos agora propor algumas ponderações sobre o consumidor na contemporaneidade. Colin Campbell desvia a máxima descartiana e proclama: "Eu compro, logo sei que existo” (2006:47). A partir de uma série de reflexões sobre a emergência de uma cultura do consumo na modernidade e sua hipervalorização na sociedade globalizada contemporânea, desenvolvida por diversos autores, poderíamos concluir que o consumo é, hoje, lugar central na constituição das referências simbólicas para a construção de representações de si e marcos de identidade. E claramente lugar de classificação, valoração e hierarquização de si e do outro, indicando as possibilidades de construção e negação de subjetividades.

Zygmuny Bauman nos lembra, em diversos de seus trabalhos, como o mundo globalizado, orientado mais pelo consumo do que pela produção, é marcado por relações de diferença entre aqueles que podem consumir e os que não podem, entre aqueles que sabem usar "corretamente" os bens e por aqueles que mesmo podendo adquiri-los não possuem o "know-how" para usá-los segundo os códigos que normatizam publicamente o mundo dos bens, em suma, entre os que são eleitos sujeitos do consumo e aqueles a quem cabe o papel secundário de espectadores do consumo alheio. Para Bauman, ambos, o rei consumista ou o alijado voyerista, são mercadorias de uma sociedade que fetichiza tanto a produção das mercadorias em si quanto a produção das subjetividades. Mas o segundo grupo, dos que não têm acesso aos bens de consumo, é ainda mais reificado que o primeiro, porque os excluídos do consumo são objeto do mesmo, com suas vidas disponíveis para a manipulação, apagamento, exclusão, invisibilidade, extermínio. Em suas palavras: "se foi o destino do fetichismo da mercadoria ocultar das vistas a substância demasiado humana da sociedade de produtores, é papel do fetichismo da subjetividade ocultar a realidade demasiado comodificada de consumidores” (2008:23).

Campbell e Bauman navegam águas comuns - a sociedade contemporânea do consumo. Para Campbell, é na cultura do consumo contemporâneo que o indivíduo experimenta, via práticas de consumo, a possibilidade de se constituir enquanto sujeito, implicando em uma nova concepção metafísica acerca do ser, atrelada à esfera do consumo. Ele indica que as comunidades de gosto (claramente associadas às práticas de consumo) são hoje forte vetor na constituição das identidades, superando eixos de raiz mais essencialista, como a nacionalidade, a classe social, os critérios de raça e gênero etc. E por seu caráter mais flexível e diversificado, tais esferas do gosto e do desejo 
acabam permitindo uma maior fluidez e dinâmica na constituição simbólica das identidades.

Para Bauman, a experiência do consumo contemporâneo não é uma tradução da flexibilidade, mas um indicativo de um mal-estar, de uma demanda contínua por satisfação de desejos que nunca irão se satisfazer, um “desejo do desejar” mais do que a conquista do objeto em si. O consumidor contemporâneo estaria condenado a ser um eterno insatisfeito, com dificuldades de se orientar, e sua busca por comunidades, de gosto ou não, seria uma tentativa de encontrar segurança em um mundo em que já lhe faltam as referências tradicionais e em que as novas estão imersas em um universo de mercadorias que nem sempre são acessíveis e, mesmo quando o são, não asseguram a satisfação e o bem viver.

Os pontos de vista de ambos convergem ainda quando apontam o lugar central da cultura do consumo na contemporaneidade. E, em especial, o lugar que o corpo ocupa neste processo. O desejo de consumo é claramente ancorado no corpo, do sujeito e/ou do outro. Citando Marcel Mauss, Ana Lucia Castro lembra que "longe da uniformidade dada pela natureza, os corpos são manipulados culturalmente e usados de maneira particular em cada sociedade (...)”. Assim, completa a autora, “o culto ao corpo pode, então, ser analisado como técnica corporal da sociedade atual, uma vez que garante melhor performance nas negociações presentes na vida cotidiana” (2007:28).

O corpo é, assim, lócus privilegiado nas relações contemporâneas de consumo. Sobre ele e nele, se depositam os adornos, marcas, vestígios, pistas, registros que permitem ao consumidor representar, privada e publicamente, seus estilos de vida, suas configurações identitárias, suas marcações existenciais. E é o corpo do outro que é objeto do desejo mais eloqüente, seja pelas sugestões que o viés romântico cristalizou de que só nos realizamos plenamente na vida em par (LÁZARO,2001), seja pela relação de projeção e identificação de que fala Edgar Morin (1986), ou seja por mecanismos de negação e exclusão, por lidarmos de forma ambígua com o outro, ao mesmo tempo objeto de desejo e de repulsa, especialmente aquele que, por motivos diversos, ferem e revelam o mundo codificado das normas e ordens.

Seguindo as proposições de diversos teóricos que vêm pensando o consumo na sociedade contemporânea, o corpo é, portanto, o principal lugar de constituição da esfera do desejo e do consumo, claramente marcado por relações de identidade e alteridade, de subjetividade e de objetificação. Consumir é, neste sentido, um consumo sensorial, que envolve o corpo enquanto matéria e enquanto simbolismo, enquanto 
artefato da natureza e da cultura, envolto, assim, em uma relação ambígua de desejo e repulsa, satisfação e frustração, sujeitos e objetos, realidade e simulacro.

Esta constatação, apresentada aqui de forma breve, nos permite retomar a série Dexter e propor algumas reflexões, já que é o corpo, mutilado e consumido pela personagem serial killer, elemento central na história narrada.

\section{Dexter e o serial killer que consome serial killers: uma representação de metaconsumo?}

Brian Javis, em seu já citado texto, lembra-nos que um dos traços mais comuns em narrativas sobre serial killers é o caráter de normalidade que o assassino aparenta ter em sua vida cotidiana. Este é o primeiro gancho que o autor utiliza para aproximar o serial killer que consome corpos em rituais macabros do consumidor contemporâneo, ele também consumidor de corpos em rituais tidos como normais, mas que, nas considerações de Javis, escondem compulsão, desperdício, sofrimento, violência, desejo de apropriação, diminuição e/ou destruição do outro, ainda que simbolicamente. O turboconsumismo contemporâneo, para utilizar o termo cunhado por Gilles Lipovetsky (2007), é potencialmente violento e destruidor, nos lembra Jarvis.

Além desses traços aproximativos, Jarvis percebe outras similitudes, de modo geral, entre a conduta do serial killer e a do consumidor contemporâneo. Em primeiro lugar, o caráter compulsivo, que muitas vezes leva à ação independentemente de uma vontade racional ou consciente. Além disso, a relação entre o desejar e a satisfação, já citada na parte anterior deste artigo, fazendo com que as etapas de preparação para o ato de consumir sejam extremamente valorizadas por prenunciarem o momento do máximo prazer, que é obtido no instante da apropriação do objeto desejado, mas, por ser fugaz e perene, leva à frustração e ao desenvolvimento de uma necessidade compulsiva de repetição daquele processo e do alargamento temporal do momento da satisfação. Como respostas, o consumidor, tal como o serial killer, busca repetir continuamente as etapas do consumo, em um jogo de insatisfação crônica, pontuado por instantes ápices de satisfação aguda, que precisam ser alongados através de práticas ritualizadas que assegurem, de alguma forma, a sensação de prolongamento do prazer.

Insaciabilidade é para Colin Campbell (2001) a palavra que define o consumo contemporâneo, e hedonismo sua meta fundamental. Para fugir de concepções predominantemente economicistas de analisar o consumo, Campbell propõe que se pense este universo não só pelos conceitos de carência e satisfação, mas principalmente 
pelas dimensões do desejo e do prazer. Com isso, o hedonismo passa a ser uma categoria central para entendermos as relações de consumo. No entanto, o consumidor moderno teria como meta um hedonismo de forma acentuadamente diferente daquele hedonismo visto como tradicional. Nas formas hedonistas tradicionais, busca-se satisfazer o prazer mediante a posse do objeto desejado. E é perceptível o esforço, quando há uma perda do objeto que garante o prazer e, portanto, a satisfação garantida, de repetir o processo que leve à aquisição daquele objeto ou de similar, para novamente ter-se a sensação do prazer satisfeito. Para Campbell, a ênfase no hedonismo tradicional está nas sensações, que devem garantir prolongadas experiências de satisfação. Há, segundo o autor, um deslocamento importante nas relações de consumo e satisfação no mundo moderno, quando as experiências cotidianas indicam uma maior fluidez e desamparo sensorial, fazendo com que as emoções passem a substituir as sensações como lugares centrais nesta busca por prazer, sugerindo aos sujeitos a ilusão de mecanismos de controle de seus impulsos hedonistas, que podem ser obtidos não somente (e quase nunca) pela satisfação via experiência sensorial, mas pelo jogo de simulações da realidade, muitas vezes via ficção, que permite vivenciar emotivamente o sensorial sem, de fato, o fazê-lo na prática. Nas palavras de Campbell:

"O hedonismo moderno apresenta todos os indivíduos com a possibilidade de ser o seu próprio déspota, exercendo total controle sobre os estímulos que experimentam e, consequentemente, sobre o prazer que obtêm. Ao contrário do hedonismo tradicional, todavia, isso não é alcançado unicamente, ou mesmo principalmente, mediante a manipulação dos objetos e acontecimentos do mundo, mas mediante um grau de controle do seu significado. Além disso, o hedonista moderno possui o poder muito especial de evocar estímulos na ausência de quaisquer sensações exteriormente geradas. Esse controle é através do poder da imaginação e proporciona à ampliação das experiências agradáveis possibilidades infinitamente maiores do que era disponível, sob o hedonismo realista e tradicional, até mesmo ao mais poderoso dos potentados. (...) É esta forma altamente racionalizada de hedonismo auto-ilusivo que caracteriza a moderna procura do prazer”. (2001:113)

Esta citação nos permite uma série de reflexões. Primeiramente, nos lembra que no consumo contemporâneo o desejar é muitas vezes, por sua enorme carga emotiva e imaginativa, mais prazeroso que a consumação do desejo em si. Por isso, nos lembra Bauman (1999), o consumidor atual é um colecionador de desejos, tanto em sua esfera simbólica - por isso a experiência seriada, fazendo com que haja constante repetição da relação desejo-satisfação-frustração-novo desejo -, quanto em sua dimensão material, com o acúmulo de objetos e marcas que figuram como troféus de conquistas passadas 
que prenunciam novos apogeus de satisfação. Não seria isso, seguindo esta linha reflexiva, a coleção de lâminas com sangue que Dexter vai acumulando na sua trajetória de mortes? Tal coleção, embora represente riscos para o serial killer, que por vezes quase é apanhado por esses rastros, praticamente os únicos que deixa em seu cuidado sistemático para não ser pego, não pode ser destruída ou abandonada porque é claramente parte do jogo do prazer, representação simbólica e material do sucesso na busca do prazer que permite ao sujeito se reconhecer enquanto tal. Da mesma forma, o consumidor contemporâneo, com suas coleções diversas de objetos e marcas, estaria exercendo, em seu papel de colecionador, uma tentativa de controlar, via aquisição e manutenção do troféu, o prolongamento da sensação do prazer e da satisfação.

Além disso, Campbell nos lembra a ambigüidade entre razão e emoção no consumo contemporâneo. Impulsivo e insaciável, mas ao mesmo tempo racional e planejado. Novamente, Dexter e sua história nos permitem traçar paralelos com o comportamento do consumidor contemporâneo. Harry, o pai de Dexter, elabora um plano pedagógico para o controle das emoções do filho, que passa a operar dentro desse código como um sujeito racional, que faz escolhas em termos de ações, não se deixando levar pelos seus impulsos e traços emocionais, planejando meticulosamente seus rituais de morte e consumo do outro, embora por vezes sujeito a imprevistos e acasos, mas quase sempre buscando o controle de suas emoções e de sua vivência do prazer. Tratase de uma compulsão, sem dúvida, mas gerenciada por planos e roteiros racionalizados e imersos na ilusão do controle e do autocontrole. Por isso também a necessidade da ação seriada, que injeta o prazer aos poucos, em medidas controladas, evitando a explosão emocional que a busca da satisfação via consumo do objeto poderia gerar.

As ambigüidades presentes em toda a série revelam as oscilações entre planejamento e acaso, razão e emoção, ordem e desordem. Sendo ao mesmo tempo herói e monstro, Dexter pode ser equiparado, simbolicamente, ao consumidor contemporâneo, supostamente sujeito racional capaz de fazer suas escolhas a partir das referências da normalidade e da ordem, ao mesmo tempo agente destruidor e desagregador em suas práticas de consumo, ego exacerbado que só entende a satisfação pela eterna repetição e muitas vezes pela destruição do outro, aquele que ameaça ou aquele que instiga o desejo.

Neste sentido, o consumidor, e mais especificamente o espectador da série, não seria o serial killer em potencial, ritualizando seu consumo de sensações através dos mecanismos de projeção e identificação com a personagem central? Mais ainda, 
acreditamos que o consumo figurativo de Dexter se constitui em espaço privilegiado de metaconsumo, em que o público pode vivenciar as experiências do hedonismo moderno - insaciedade; necessidade de repetição seriada; ilusão de controle das emoções e de um certo distanciamento entre o jogo imaginativo e a experiência sensorial propriamente dita; angústia frente à possibilidade do fim do momento que garante a satisfação, levando à necessidade de colecionar o objeto que garante o prazer e prolongá-lo através de artifícios diversos, dentre os quais a criação de rituais preparatórios para a consumação do consumo; celebração do corpo como espaço preferencial do desejo; dentre outras -, sem necessariamente ter que passar fisicamente por elas. Dexter Morgan, seria, nesse caso, o avatar do consumidor serial killer, insaciável e compulsivo, ao mesmo tempo racional e planejador, iludido em seu autocontrole e devorador do outro, do corpo alheio, objeto ambíguo de prazer e repulsa, ameaça à ordem e ao mesmo tempo índice claro de nossa adesão ao mundo da desordem, mesmo que sob a rubrica da norma e dos mecanismos de controle.

Dexter, neste sentido, nos parece um objeto muito interessante para nossas reflexões. Por seu conteúdo, nos permite uma discussão sobre a prática do consumo em série, tendo o corpo como foco principal e a constituição da identidade através das relações de alteridade. Mas também enquanto objeto de consumo em si, bem a ser adquirido, também mercadoria a ser colecionada, nos lembrando, mais uma vez, o que afirmam Douglas e Isherwood:

“(...) a função essencial do consumo é sua capacidade para dar sentido. Duvidemos da idéia da irracionalidade do consumidor. Duvidemos que as mercadorias servem para comer, vestir-se e se proteger. Duvidemos de sua utilidade e tentemos colocar em troca a idéia de que as mercadorias servem para pensar" (apud CASTRO, 2004:19).

Retomando a proposta inicial desse artigo, a partir das equiparações propostas por Brian Jarvis entre o serial killer e o consumidor contemporâneo, acreditamos que o consumidor de uma série que tem como tema um serial killer que consome serial killers seria, neste sentido, a representação mais acentuada desses traços, fazendo com que a série, dessa forma, sirva para entreter e também para pensar. Em uma analogia com o que se configura como o mundo das práticas de consumo na sociedade contemporânea, em que o consumo é fragmentado e possibilita a fluidez das configurações identitárias, marcando a relação com o outro pela impermanência e pelo descarte, em que o prazer realiza-se no objeto de desejo e o desejo é desejo de desejar, podemos pensar que o consumo de uma série televisiva em que a personagem principal também consome em 
série suas vítimas (elas também consumidoras em série de outros corpos que, por sua vez, também são consumidoras potenciais e reais de bens diversos) funciona como um jogo de espelho e reflexos, mandalas e camadas que se superpõe e se atravessam, em um processo de metaconsumismo que revela a riqueza dos objetos do campo da comunicação, esses também, para nós, pesquisadores do campo, objetos de consumo sobre os quais temos a ilusão do controle e a sensação da angústia permanente do que nos escapa.

\section{Referências bibliográficas}

BARBOSA, Lívia e CAMPBELL, Colin (orgs.). Cultura, consumo e identidades. Rio de Janeiro, FGV, 2006.

BAUMAN, Zygmunt. Globalização. As conseqüências humanas. Rio de Janeiro, Jorge Zahar Editor, 1999.

BAUMAN, Zygmunt. Vida para consumo. A transformação das pessoas em mercadoria. Rio de Janeiro, Jorge Zahar Editor, 2008.

BRASILIENSE, Danielle. "Os sentidos midiáticos da ordem e da monstruosidade em Dexter". Trabalho selecionado para ser apresentado no GT Cultura das Mídias da Compós 2009. Belo Horizonte, 2009.

CAMPBELL, Colin. A ética romântica e o espírito do consumismo moderno. Rio de Janeiro, Rocco, 2001.

CASTRO, Ana Lucia. “Corpo, consumo e mídia”. IN: Comunicação, mídia e consumo. Vol.1, ano 1, n 1. São Paulo, ESPM, maio de 2004.

JARVIS, Brian. “Monsters Inc.: serial killers and consumer culture”. IN: Crime. Media. Culture. Sage Publications, 2007.

DOUGLAS, Mary e ISHERWOOD, Baron. O mundo dos bens. Para uma antropologia do consumo. Rio de Janeiro, ed. UFRJ, 2006.

LÁZARO, André. Amor, do mito ao mercado. Petrópolis, Vozes, 1997.

LIPOVETSKY, Gilles. A felicidade paradoxal. Ensaio sobre a sociedade de hiperconsumo. São Paulo, Companhia das Letras, 2007.

MORIN, Edgar. Cultura de massas no século XX. Vol. 1 e 2. Rio de Janeiro, Forense Universitária, 1986. 